\title{
GLOTTALIC CONSONANTS IN SINDHI AND \\ PROTO-INDO-EUROPEAN
}

1. In 1973 Gamkrelidze and Ivanov suggested on typological grounds that the reconstructed voiced occlusives of the Indo-European proto-language were actually glottalic. ${ }^{1}$ Elsewhere I have argued that this hypothesis is supported by comparative evidence from Baltic ${ }^{2}$ and Armenian ${ }^{3}$ and offers an explanation for the lengthening in Latin äctus, léctus (Lachmann's law) and the devoicing in Sanskrit yuktáh $<*^{*}$-gt-, vásuttih $<*^{*}$-dHt-, as opposed to dugdháh $<*$-ght-, vásudhitih $<*_{-d h H t-.}{ }^{4} \mathrm{I}$ have not discussed the Sindhi material, which will be the subject of the present article.

2. Apart from the usual obstruents which are found in the other Indo-Aryan languages (voiced and voiceless, aspirated and unaspirated), Sindhi possesses a series of voiced implosive stops, which will be denoted by ' $b,{ }^{\prime} d,{ }^{\prime} j,{ }^{\prime} g$ in this article. ${ }^{5}$ There is no dental implosive stop. The phonemic status of the implosives is beyond doubt, cf. $b a k h^{u}$ 'sacrifice of a goat', 'bakhu 'embrace', dithō 'bold', 'dithōo 'seen', jaü 'barley', 'jaü 'lac', gacu 'mortar', 'gacu 'much'. ${ }^{6}$ The topic of this article is their historical origin.

3. As Turner points out, "a detailed examination of the words in which they occur shows that initially ' $g^{\prime} j{ }^{\prime} d{ }^{\prime} b$ correspond to initial $g-, j-(d y-), d-, b-(d v-)$ in Sanskrit, and intervocalically to consonant groups in Sanskrit that in Prakrit became $-g g--j j--d d-(-d d-)-b b-(-v v-)$, while the simple voiced stops in Sindhî, $g j d b$, are the result of special conditions and in most cases (where not occurring in loan-words from other languages) are descendants of Primitive Indian sounds other than $g j d b$. The simple voiced dental $d$, except in the group $n d$, is found only in loan-words. That is to say, except for certain specific conditions, Sindhi has shifted Primitive Indian $g j d b$ to ' $g^{\prime} j^{\prime} d{ }^{\prime} b . " 7$

4. The rise of the glottalic articulation which is characteristic of the Sindhi implosives can hardly be attributed to external influence because the neighbouring Dravidian (Brahui), Iranian (Baloči), and Indo-Aryan languages do not present anything comparable, with the exception of the westernmost dialect of the closely related Lahnda language. The southern (Kacchi) and eastern (Thareli) dialects of Sindhi do not have implosives. On the other hand, it is difficult to perceive an internal motivation for the rise of the glottalic consonants, which are not found elsewhere in the Indo-Aryan linguistic area. Since the Sanskrit reflexes of the sounds 
for which Proto-Indo-European glottalic articulation has been assumed are reflected as implosives in Sindhi, e.g. 'dian $u$ 'to give' (PIE *dō-), we must consider the possibility that the latter language has preserved an archaism which was lost elsewhere.

5. As Turner points out, "the simple voiced stops - $g j d b$ - can result from the disaspiration of the corresponding aspirated voiced stops - $g h j h d h b h$. A voiced aspirate when followed by an aspirate or by $h$ in the same word lost its aspiration and became the corresponding simple voiced stop without glottal closure. It makes no difference whether $h$ represents a Sanskrit intervocalic sibilant or has been inserted simply to avoid hiatus." 8 Examples: bathī 'quiver' (Skt. bhástrāa), ditḥō 'bold' < * dhithō (Skt. dhrștáa), gāhu 'fodder' (Skt. ghäsá-), cf. 'gähu, 'bait'< grāsa-. It follows that the rise of the implosives was anterior to the dissimilation of voiced aspirates before another aspirate or $h$.

6. A surd stop preceded by a nasal becomes the corresponding voiced stop, which remains without glottal closure. The original voiced stops preceded by a nasal are completely assimilated to the preceding nasal. In the group stop $+r$, the $r$ is lost, except when the stop is a dental. In the latter case, the dental becomes a cerebral and the $r$ (except in South Sindhi) remains. Even when the resultant cerebral is voiced, there is no glottal closure, e.g. drākha 'a small grape' (drākssā), ändrō 'entrails' (āntra-), candru 'moon' (candrá-). Thus, where the voiced stop is preceded by a nasal or followed by $r$ there is no glottal closure. These clusters do not offer a basis for a relative chronology because it cannot, at this point, be decided whether the glottal closure arose in ' $g \bar{a} h u$ 'bait' after the loss of $r$ in gräsa-, or was lost secondarily in $d r a \bar{k} k h^{a}$.

7. Initial $v y$-became $w$ - in Sindhi, e.g. wäghu 'tiger' (Skt. vyāghrá-), but intervocalic - vy- became - $b$ - without glottal closure, e.g. siban $u$ 'to sew' (stvyati), 'katabu 'business' (kártavya-). It follows that the rise of the intervocalic implosive -' $b$ - from $-b r-,-r b-$, and $-d v$ - was anterior to the development of $-v y$-into a bilabial stop. The rise of ' $b$ from initial and intervocalic $d v$ and the rise of ' $j$ from intervocalic $d y$ do not offer a basis for a relative chronology because the glottal closure may have been a feature of the dental obstruent before the sound change already, e.g. ' $b a$ 'two', 'büjo 'second' (Skt. $d v \bar{a}, d v i t \underline{t} y a-), u$ 'batan u "perfumed flour to rub the body with" (udvartana-), a $a^{j} u$ 'to-day' (adyá).

8. Sindhi, like Kashmiri and Sinhalese, keeps Skt. $j$ and $y$ apart. The former became ' $j$, the latter $j$, e.g. $j \bar{j}, j \bar{a}$ 'who' (yáh, yâa), jō 'because' (yátah), janyō ‘sacred cord' (yajñopavitáa-), jăhu 'coitus' (yäbha-). It follows that the rise of the implosive ' $j$ was anterior to the development of initial $y$ into a stop. In the same way, Skt. 
-iya- (Pali -iya- or -iyya-) is reflected in Sindhi as -ija-, while Skt. -idya-is reflected as Sindhi -i'ja-, e.g. 'dijan ${ }^{u}$ 'to be given' (dìyáte, Pali diyyati, Prakrit dijjal), chi'jan $u$ 'to be broken' (chidyate). Cf. also bhänējōo 'sister's son' (bhägineyaka-, Pali bhāgineyya-), mātrējō 'belonging to a stepmother' (*mātreya-, Pali matteyya-), sēja 'couch' (sayyä, Prakrit sejjä), as opposed to bha'jan $u$ 'to be broken' (bhajyate), upa'jan $u$ 'to be produced' (utpadyate), we' $j u$ 'doctor' (vaidya-). Thus, 1 assume that $-j$ - is the regular reflex of intervocalic - $y y$ - in Sindhi.

9. The treatment of $-r y$ - and $-r v$-differs from that of $-y y$-and $-v y$-in the presence

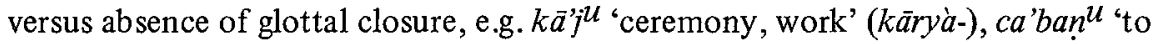
chew' (carvati), sejja 'couch' ('sayyā), katabu 'business' (kártavya-). We have to conclude that $r$ was not assimilated to a following $y$ or $v$, but developed into glottal closure. I think that $-r y$ - and $-r v$ - became $-d y$ - and $-d v$ - at an early stage and subsequently shared the regular development of these clusters in Sindhi. They do not offer a basis for a relative chronology because the glottal feature may or may not have been present in the original clusters $-d y$ - and $-d v$ - at the time when the obstruent replaced the alveolar or retroflex flap in $-r y$ - and $-r v$.

10. The facts which have been discussed so far do not inhibit the identification of Sindhi and Proto-Indo-European glottalization. In particular, Sindhi may have preserved the glottal closure which has been surmised as a feature of the PIE voiced occlusives except for certain specific environments. There are a number of instances where the identification is impossible, however. First of all, the unaspirated voiced stops which came into being as a result of Grassmann's law are reflected as implosives in Sindhi, e.g. 'badhō 'bound' (baddhá), 'ḍahi 'curds' (dádhi), 'jangh ${ }^{a}$ 'leg' (jänghä), 'ginhan ${ }^{u}$ 'to buy' (grhnāt $t$ ). If the identification of Sindhi and PIE glottalization is to be upheld, we must assume that the initial consonant of these words became glottalic as a result of the aspiration dissimilation. This is no serious objection because there was no series of unaspirated voiced stops without glottal closure at the time of the dissimilation if PIE glottalization had not yet been lost at that stage.

11. Besides, there is an implosive in the words $p \bar{e}^{\prime} j u$ 'drinking', $p \bar{e}^{\prime} j a, p \bar{e}^{\prime} j \bar{l}$ 'ricewater', $p \bar{e}^{\prime} j u, p \bar{e}^{\prime} j \bar{o}$ 'watering land after sowing' (Pali peyya-). The implosive cannot continue $-y y$-, which yielded $-j$ - (see above). I think that the glottal closure is the reflex of the laryngeal in the PIE root *poH( $i)$ - 'drink'. The preservation of the laryngeal before the semivowel in this word-family is a consequence of its particular root structure. The development of the laryngeal into glottal closure gave rise to a marginal phoneme - $-y$-in pre-Sindhi, which was to merge with $-^{\prime} j$ - from $-d y$ - and $-j y-.9$ 
12. The hypothesis that the laryngeal was preserved in the position before a semivowel up to a stage which was posterior to the rise of the Sindhi implosives is supported by the absence of glottal closure in the words $j \bar{\imath} u$ 'living being' (jiz $v a^{\prime}$ ) , jiaró 'alive' (jivalá-), jian ${ }^{u}$ 'to live' (jî́vati). Turner attributes the absence of glottal closure in these words to the following $-\vec{l}_{-} .^{10}$ This is unsatisfactory because there is an initial implosive in ' $j i b h^{a}$ 'tongue' (jihvá) and it is not clear why the length of the following vowel should have caused the loss of the initial glottal closure. I assume that the latter was lost by dissimilation before the glottal closure which had developed from the laryngeal of PIE ${ }^{*} g{ }^{w} i H(u)$ - 'live', which had been preserved before the semivowel and was subsequently lost. Several conjectures can be made in connection with jirro 'cummin-seed' (jiraka-), none of which seems to be demonstrable.

13. Moreover, there is an implosive in su'janu 'to be heard' ('srüyáte, Pali suyyati), su'jan $u$ 'to be swollen' ('süyate), u'janu 'to be woven' (üyate). Here again I assume earlier $-' y$-, where the glottal closure continues a laryngeal which was original in setverbs and spread to anit-verbs in the passive. In nïan ${ }^{u}$ 'to be carried away' (nīyate) etc. the glottal closure was apparently lost between $-i$ - and $-y$-at an early stage.

14. One may wonder if it is probable a priori that an archaic feature which was lost elsewhere in the Indo-Aryan linguistic area should be preserved in Sindhi. It must be remembered that Sindhi belongs to the more conservative dialects, e.g. in the preservation of the distinction between Skt. $j$ and $y$, which it shares with Kashmiri and Sinhalese, and in the preservation of $r$ after a dental obstruent. Since there are indubitable traces of early dialectal diversity in the Rgveda, ${ }^{11}$ the possibility that Sindhi has preserved an archaism which was lost elsewhere cannot be rejected a priori. The original Indian script does not provide the means of distinguishing between glottalic and plain voiced obstruents, which became phonemically relevant only as a result of the Sindhi dissimilation of voiced aspirates before another aspirate or $h$.

15. In any case, the Sindhi material cannot be adduced in support of "the general diachronic hypothesis that at least one source of injectives might be a sound shift from voiced plain to voiced implosive stops". ${ }^{12}$ The comparative evidence points the other way.

Faculteit 'der Letteren, Leiden, The Netherlands 


\section{NOTES}

1 Phonetica 27, $150 \mathrm{ff}$.

2 Baltistica 13 (1977), $319 \mathrm{ff}$.

3 Studia Caucasica 4 (1978), 9 ff.

4 Cf. IF 83 (1978), $107 \mathrm{ff}$.

5 On the phonetics see P. Nihalani, Phonetica 29 (1974), $193 \mathrm{ff}$.

6 These examples are taken from R. L. Turner, 'The Sindhi recursives or voiced stops preceded by glottal closure', BSOS 3 (1924), 301 - 315, reprinted in his Collected Papers 1912-1973

(London 1975), 192-205. Turner gives a few dozens of minimal pairs. His article serves as a basis for the following analy sis.

7 Loc. cit., p. 305 (reprint p. 196).

8 Loc. cit., p. 311 f. (reprint p. 202).

9 A similar merger of laryngeals with the glottal closure of the PIE voiced occlusives took place in Baltic and Slavic, cf. Baltistica 13, 319 ff.

10 Loc. cit., p. 309 (reprint p. 199).

11 Cf. M. B. Emeneau, 'The dialects of Old Indo-Aryan', Ancient Indo-European dialects (Berkeley and Los Angeles 1966), $123 \mathrm{ff}$.

12 J. H. Greenberg, IJAL 36 (1970), p. 134. 